\title{
Erratum to: Letter to the Editor: Minimizing the Access Trauma of Laparoscopic Sleeve Gastrectomy: the Transoral Specimen Extraction Technique
}

\author{
Wah Yang ${ }^{1} \cdot$ Jingge Yang $^{1} \cdot$ Cunchuan Wang ${ }^{1}$
}

Published online: 12 January 2016

(C) Springer Science+Business Media New York 2016

\section{OBES SURG}

DOI 10.1007/s11695-015-2014-y

The text, figure captions, and references were missing in the published letter to the editor. The complete letter to the editor follows:

Dear Editor:

We read with great interest the article by Marco Maria Lirici et al., titled "Minimizing the Access Trauma of Laparoscopic Sleeve Gastrectomy: the Transoral Specimen Extraction Technique" [1]. We appreciate them introducing the natural orifice specimen extraction (NOSE) technique that applied in laparoscopic sleeve gastrectomy (LSG).

We agree that the NOSE technique is able to minimize the access trauma of LSG in certain extent $[1,2]$. But we have concerns in several aspects. By using the NOSE technique the authors used, there is a risk that tearing of the esophagus by the staples in the resected stomach may happen. There is also

possibility to damage of the blood vessels of the esophagus and cause bleeding. This risk can be even elevated when the size of the resected stomach is large. Besides, there is friction when extracting the stomach via the esophagus, there may have rupture of the esophagus and that may cause infection. All these result a contraindication of the NOSE that patients with large stomach size may not be suitable to use this technique.

In our experience, the specimen is always put into a retrieval bag to prevent the direct contact with the incision, so to decrease the incidence of site infection. The grasped specimen together with the retrieval bag can be either withdrawn via the $12-\mathrm{mm}$ incision at the right side of the abdomen or at the umbilical incision. Then, the specimen is extracted from the incision gently to keep intact and avoid disruption (Figs. 1 and 2). After specimen extraction, the $12-\mathrm{mm}$ incision is closed with hernia repair device to lower the chance of incisional hernia [3].

The online version of the original article can be found at http://dx.doi.org/ 10.1007/s11695-015-2014-y.

Cunchuan Wang

twcc@jnu.edu.cn

Wah Yang

yangwah@qq.com

Jingge Yang

yjgduke@126.com

1 Department of General Surgery, First Affiliated Hospital of Jinan University, 613 Huangpu Avenue West,

Guangzhou 510630, Guangdong Province, China 


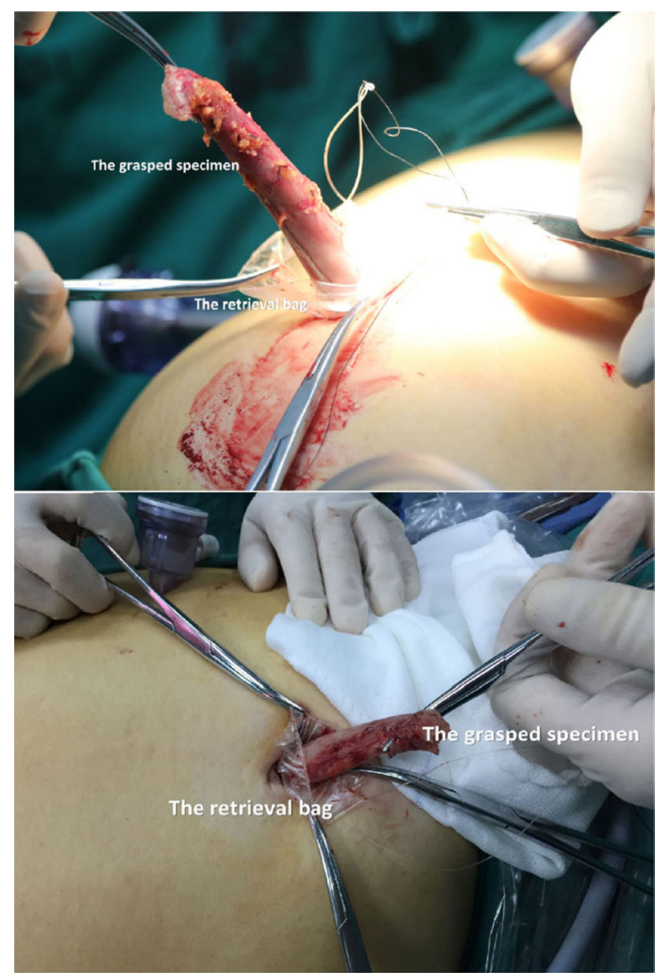

Fig. 1 The grasped specimen is withdrawn via the $12-\mathrm{mm}$ incision in a retrieval bag

This technique is also feasible in a $10-\mathrm{mm}$ incision. Moreover, it can be more time saving than that of the NOSE.

In conclusion, specimen extraction is the last but important step in LSG that different surgeons may have different biases

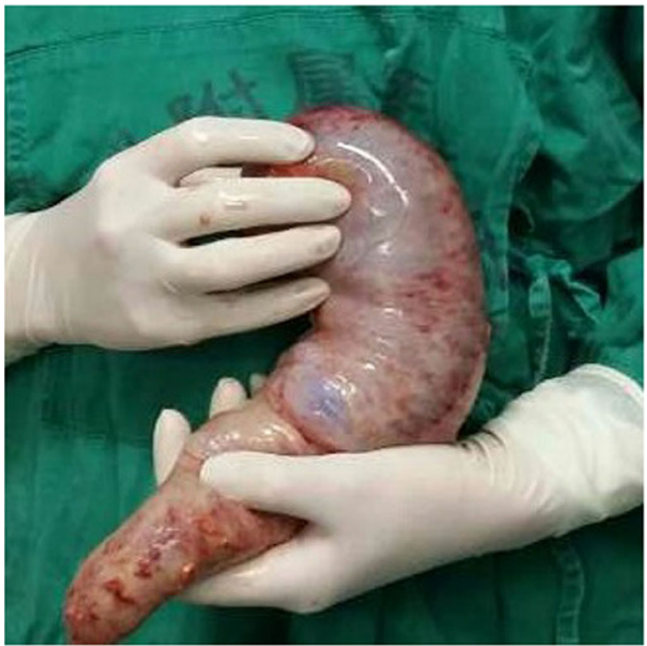

Fig. 2 The extracted stomach is intact without disruption

on the methods. Large sample size and randomized controlled trial may be needed for comparison of the different methods.

\section{References}

1. Lirici MM, Romeo V, Simonelli L, Tierno S, Vitelli CE. Minimizing the access trauma of laparoscopic sleeve gastrectomy: the transoral specimen extraction technique. Obes Surg. 2015 Oct 16.

2. Alley JB, Fenton SJ, Peterson RM. The "Tip-Stitch": a time-saving technique for specimen extraction in sleeve gastrectomy. Obes Surg. 2009;19(7):926-7.

3. Yang W, Wang C, Yang J. Precise laparoscopic Roux-en-Y gastric bypass: a new concept in bariatric and metabolic surgery. Surgical Laparosc Endosc Percutan Tech. 2015;25(3):e98-e100. 